\title{
ARTICLE \\ Ventral pallidum is essential for cocaine relapse after voluntary abstinence in rats
}

Mitchell R. Farrell ${ }^{1}$, Christina M. Ruiz ${ }^{1}$, Erik Castillo ${ }^{1}$, Lauren Faget ${ }^{2}$, Christine Khanbijian ${ }^{1}$, Siyu Liu ${ }^{1}$, Hannah Schoch ${ }^{1}$, Gerardo Rojas ${ }^{1}$, Michelle Y. Huerta ${ }^{1}$, Thomas S. Hnasko ${ }^{2,3}$ and Stephen V. Mahler (iD)

\begin{abstract}
Addiction is a chronic relapsing disorder, and during recovery many people experience several relapse events as they attempt to voluntarily abstain from drug. New preclinical relapse models have emerged that capture this common human experience, and mounting evidence indicates that resumption of drug seeking after voluntary abstinence recruits neural circuits distinct from those recruited during reinstatement after experimenter-imposed abstinence, or abstinence due to extinction training. Ventral pallidum (VP), a key limbic node involved in drug seeking, has well-established roles in conventional reinstatement models tested following extinction training, but it is unclear whether this region also participates in more translationally relevant models of relapse. Here we show that chemogenetic inhibition of VP neurons decreased cocaine-, context-, and cue-induced relapse tested after voluntary, punishment-induced abstinence. This effect was strongest in the most compulsive, punishment-resistant rats, and reinstatement was associated with neural activity in anatomically defined VP subregions. VP inhibition also attenuated the propensity of rats to display "abortive lever pressing," a species-typical risk assessment behavior seen here during punished drug taking, likely resulting from concurrent approach and avoidance motivations. These results indicate that VP, unlike other connected limbic brain regions, is essential for resumption of drug seeking after voluntary abstinence. Since VP inhibition effects were strongest in the most compulsively cocaine-seeking individuals, this may also indicate that VP plays a particularly important role in the most pathological, addiction-like behavior, making it an attractive target for future therapeutic interventions.
\end{abstract}

Neuropsychopharmacology (2019) 44:2174-2185; https://doi.org/10.1038/s41386-019-0507-4

\section{INTRODUCTION}

Addiction is characterized by persistent drug use despite negative consequences and a lasting vulnerability to relapse after protracted periods of abstinence [1-3]. Typically, human addicts eventually recognize the negative consequences of their behavior and choose to cease using drugs-a decision they usually renege upon when tempted by drug cues, small doses of drug, or stressors [4]. In rodent relapse models, reinstatement of seeking is triggered by analogous stimuli, usually following a period of imposed abstinence from drug (incubation) or explicit extinction training. Recently, voluntary abstinence-based rodent relapse protocols have emerged, modeling addicted people who choose to stop using drugs due to mounting negative life consequences, rather than ceasing use due to extinction training or external forces [5-9]. This is important because, in rodents, the neural substrates underlying reinstatement differ based upon how abstinence was achieved, be it experimenter-imposed, through extinction training, or through voluntary cessation due to punishment or availability of more attractive reinforcers [10-15]. If the brain substrates of human relapse similarly depend upon why a person stopped using drugs, then considering these factors in preclinical models will be essential for developing effective interventions to treat addiction.
A hallmark of addiction is an inability to limit drug intake in the face of negative life consequences. This can be modeled in rodents by training them to self-administer drugs, then introducing consequences to continued use, such as co-delivered footshock [5, 6, 16-20]. As in humans, most rodents readily suppress their drug intake when negative outcomes begin to result from continued use. However, a subset of rodents show punishment-resistant drug intake [17, 21-23], similar to the proportion of humans who use drugs and ultimately become addicted [24]. Punishment-resistant rats also exhibit elevated reinstatement of cocaine and methamphetamine seeking $[17,25]$, suggesting that compulsive use and relapse liability involve common underlying neural mechanisms. Indeed, the circuitry underlying compulsive cocaine intake overlaps with the limbic substrates of reinstatement behavior, at least when tested following extinction training [23, 26-29].

One brain region that has emerged as being crucial for motivated behavior is the ventral pallidum (VP), the main efferent target of nucleus accumbens (NAC) [30-35]. VP is thought to help translate motivation into action [36-39], and accordingly, VP neural activity encodes reward motivation in rodents, monkeys, and humans [40-42], including for cocaine [43]. VP is also required for seeking of several abused drugs [44-49] and for cocaine reinstatement triggered by cues, stress, or cocaine following

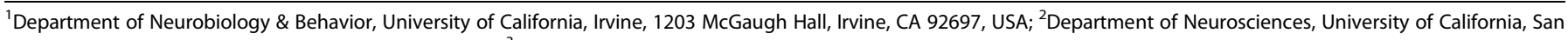
Diego, 9500 Gilman Drive, La Jolla, CA 92093, USA and ${ }^{3}$ VASDHS Research Service, 3350 La Jolla Village Drive, San Diego, CA 92161, USA

Correspondence: Stephen V. Mahler (mahlers@uci.edu)

These authors contributed equally: Mitchell R. Farrell, Christina M. Ruiz.

Received: 23 May 2019 Revised: 22 August 2019 Accepted: 24 August 2019

Published online: 2 September 2019 
extinction training $[47,50,51]$. Notably, VP is a heterogeneous structure, with functionally and anatomically distinct rostral/caudal and dorsolateral/ventromedial subregions that mediate distinct aspects of reward seeking [43, 47, 52-59]. For example, rostral VP mediates cue induced, whereas caudal VP mediates primed reinstatement of cocaine seeking following extinction training [47]. The NAc shell input-receiving ventromedial and NAc corereceiving dorsolateral VP subregions are also differentially involved in cocaine-taking behaviors $[43,52,60]$. Given these results and recent findings that VP contains phenotypically distinct populations of reward- and aversion-related neurons [30-32, 61-63], VP's role in drug seeking under translationally relevant mixed motivation circumstances was of interest to us.

Here we explore effects of transiently and reversibly inhibiting VP neurons of punishment-resistant or -sensitive rats with designer receptors (designer receptors exclusively activated by designer drugs (DREADDs)) [64], determining effects on punished cocaine seeking, context, discrete cue, and primed reinstatement after voluntary abstinence, and cocaine-induced locomotion. We also assessed relapse-related Fos in VP subregions. We found that chemogenetic VP inhibition reduced cue-, cocaine primed-, and context-induced relapse to cocaine seeking, and VP subregions are robustly Fos activated during exposure to cocaine or cocaine + punishment contexts. These studies shed light on the functions of this essential but understudied nucleus within cocaine addiction-related neural circuits.

\section{METHODS}

\section{Subjects}

Male ( $n=50$; mean \pm SEM body weight $=345 \pm 6 \mathrm{~g}$ at the start of self-administration) and female $(n=36$; mean \pm SEM $=226 \pm 4 \mathrm{~g})$ Long-Evans rats were bred at the University of California, Irvine or obtained from Envigo and were pair housed on a 12-h reverse light/dark cycle (testing in dark phase), with ad libitum food and water throughout experiments. Procedures were approved by the $\mathrm{UCl}$ Institutional Animal Care and Use Committee and are in accordance with the NIH Guide for the Care and Use of Laboratory Animals [65].

\section{Surgery}

Rats were anesthetized with ketamine $(56.5 \mathrm{mg} / \mathrm{kg})$ and xylazine $(8.7 \mathrm{mg} / \mathrm{kg})$, administered the non-opioid analgesic meloxicam $(1.0 \mathrm{mg} / \mathrm{kg})$, and implanted with in-dwelling jugular catheters exiting the dorsal back. In the same surgery, they also received bilateral viral vector injections $(250-300 \mathrm{~nL})$ into VP $(\mathrm{mm}$ from Bregma; AP: 0.3, ML: \pm 1.8 , DV: $-8.2 \mathrm{~mm}$ ) with pressure injections using a Picospritzer and glass micropipette. Figure 1 describes the procedures.

Viral constructs

To transduce VP neurons with hM4Di inhibitory DREADDs, we used a human synapsin (hSyn) promoter-driven adeno-associated virus (AAV) with mCitrine $(n=44 ; \mathrm{U}$ North Carolina vector core: $A A V 2-h S y n-H A-h M 4 D(G i)-I R E S-m C i t r i n e ;$ titer $=2.6 \times 10^{12}$ virus particles $/ \mathrm{mL}$ ) or mCherry ( $n=16$; Addgene: AAV2-hSyn-hM4D(Gi)- $m$ Cherry; titer $=7 \times 10^{12}$ viral genomes $\left.(\mathrm{vg}) / \mathrm{mL}\right)$ reporter. To control for non-specific impact of viral transduction and clozapine- $\mathrm{N}$-oxide (CNO) in the absence of DREADDs, an enhanced green fluorescent protein (eGFP)-only reporter without DREADDs ( $n=7$; Addgene: AAV2-hSyn-eGFP; titer $=3 \times 10^{12} \mathrm{vg} / \mathrm{mL}$ ) was employed in a group of control rats [66-68].

\section{Anatomical analysis of DREADD expression}

hM4Di DREADD/reporter expression was visualized with immunofluorescent amplification and substance $\mathrm{P}$ co-stain demarcating VP borders (see Table S1 for antibody information). Histological quantification was performed by an observer blind to group and behavioral results. Rats with at least $40 \%$ of VP volume expressing DREADDs/reporter and at least $40 \%$ of virus expression localized within VP borders were considered hits $(n=46$; male $=26$; female $=20$ ). Some leakage into the adjacent lateral preoptic area and horizontal limb of the diagonal band was detected in most rats, but if rats had $>60 \%$ of DREADD expression localized outside VP, they were considered "misses" $(n=13)$. Since rats with extra-VP DREADD expression did not behaviorally differ from fluorophoreonly rats (no main effect of group or CNO treatment on reinstatement of any kind, $F s<1.29$, ps $>0.27$; Fig. S1), they were combined into a single control group $(n=20$; male $=10$; female $=10$ ) for subsequent analyses of CNO effects in the absence of VP DREADDs.

RNAscope analysis of DREADD expression in VP neurons Paraformaldehyde (PFA)-fixed brains from cocaine-naive male rats were serially cut $(16 \mu \mathrm{m})$ on a cryostat and mounted directly onto glass slides. Sections were stored at $-80^{\circ} \mathrm{C}$ until processing for RNAscope Multiplex Fluorescent assay (Advanced Cell Diagnostics). Briefly, sections were warmed on a hot plate for $30 \mathrm{~min}$ at 60 ${ }^{\circ} \mathrm{C}$, then boiled at $100^{\circ} \mathrm{C}$ for $6 \mathrm{~min}$ in target retrieval solution. Sections were then dehydrated in $100 \%$ ethanol and treated with protease (pretreatment reagents, cat. No. 322380). RNA hybridization probes included antisense probes against rat Gad1 (316401C1) and Slc17a6 (317011-C3), respectively, labeled with alexa-488 and atto-647 fluorophores. Slides were then incubated with rabbit anti-DsRed primary antibodies (1:2000, Catalog \#: 632496, Clontech) and donkey anti-rabbit AlexaFluor 594 secondary antibodies (1:400, \#711-585-152, Jackson ImmunoResearch), counterstained with 4,6-diamidino-2-phenylindole, and coverslipped using Fluoromount-G mounting medium. Images for cell counting were taken at $\times 63$ (1.4 NA) magnification using a Zeiss AxioObserver Z1 widefield Epifluorescence microscope with a Zeiss ApoTome 2.0 for structured illumination and Zen Blue software. An average of $177 \pm 9$ cells positive for AAV-hSyn-hM4D (Gi)-mCherry were counted per brain ( $n=3$ rats).

\section{Drugs}

Cocaine $\mathrm{HCl}$ (NIDA) was dissolved in $0.9 \%$ saline and was available for self-administration at $0.2 \mathrm{mg} / 50 \mu \mathrm{L}$ infusion for male rats $(\sim 0.58 \mathrm{mg} / \mathrm{kg} /$ infusion) and $0.15 \mathrm{mg} / 50 \mu \mathrm{L}$ infusion for female rats ( $0.66 \mathrm{mg} / \mathrm{kg} /$ infusion) [69, 70]. Cocaine $(10 \mathrm{mg} / \mathrm{kg})$ was used for primed reinstatement and locomotion testing. CNO was dissolved in a vehicle of $5 \%$ dimethyl sulfoxide in $0.9 \%$ saline

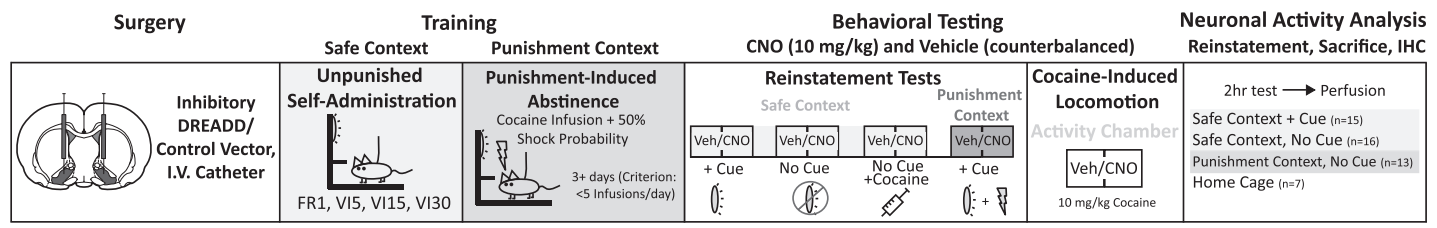

Fig. 1 Schematic of experimental timeline. Following DREADD or control AAV injection, rats underwent cocaine self-administration and punishment training, followed by reinstatement and cocaine-induce locomotor testing. A final relapse test preceded sacrifice for neuronal activity (Fos) analysis. Light/green shading = safe context, dark/red shading = punishment context 
and injected intraperitoneally at $10 \mathrm{mg} / \mathrm{kg}, 30 \mathrm{~min}$ prior to behavioral testing.

Behavioral testing apparatus

Self-administration training and testing took place in Med Associates operant chambers within sound-attenuating boxes, equipped with two retractable levers with white lights above them and a tone generator. Cocaine-induced locomotion testing was conducted in $43 \times 43 \times 30.5 \mathrm{~cm}^{3}$ Med Associates locomotor testing chambers.

Behavioral training summary

We employed a model of punishment-induced abstinence from self-administered cocaine, followed by repeated reinstatement testing. Rats initially self-administered cocaine in a "safe context," then in a distinct "punishment context," where they learn to abstain from cocaine due to co-administration of footshock with $50 \%$ of cocaine infusions. After voluntary abstinence was achieved in all rats, a series of reinstatement tests in the safe and punishment contexts were conducted, each tested after vehicle and $\mathrm{CNO}$ on separate days, $48 \mathrm{~h}$ apart (order counterbalanced within each reinstatement test modality, as depicted in Table S2).
Self-administration training in safe context

We employed a punishment-induced abstinence/relapse protocol modeled after previous reports [5, 6, 8, 10, 20, 71-73]. Initial 2-h self-administration sessions occurred in a "safe context," signaled by the presence of a white or red house light, peppermint or orange scent, and plain or polka dot pattern walls (randomly assigned). Rats received five daily sessions of fixed ratio 1 (FR1) training where an active lever press delivered a 3.6-s intravenous cocaine infusion and concurrent stimulus light +2.9 $\mathrm{kHz}$ tone. A $20 \mathrm{~s}$ timeout period (signaled by dimming of the house light) followed each infusion/cue presentation, during which additional lever presses did not yield cocaine delivery. Following FR1 training to criterion ( $>10$ infusions/day), rats then completed 3 days of variable-interval 5 schedule (VI5), on which an active lever press initiated a timer with an average duration of $5 \mathrm{~s}$, and another press after that interval delivered a cocaine infusion+light/tone cue. The VI schedule was increased to VI15 for the next 3 days, then VI30 for an additional 3-6 days until performance stabilized (Fig. S2). VI schedules promote resistance to extinction [74], providing a high baseline of responding in relapse tests, so we followed methods of prior reports using this procedure [5, 10, 20, 71, 73]. Pressing on an inactive lever was recorded but had no consequences.

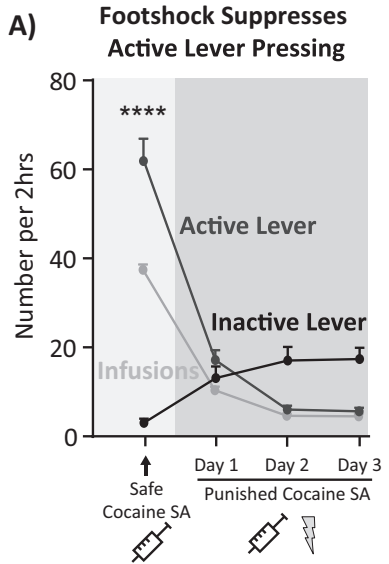

B)

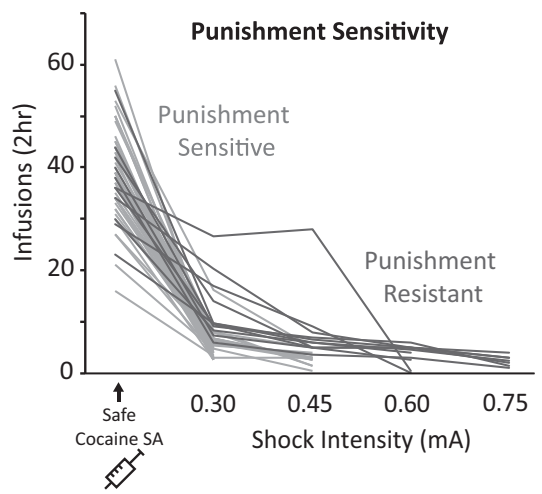

D) Punishment Sensitivity and Reinstatement

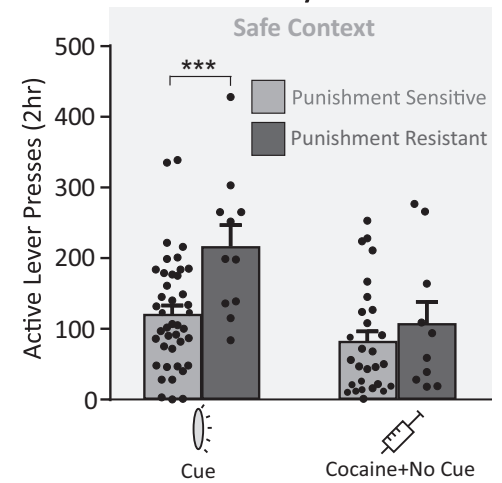

Punishment Sensitivity

E)

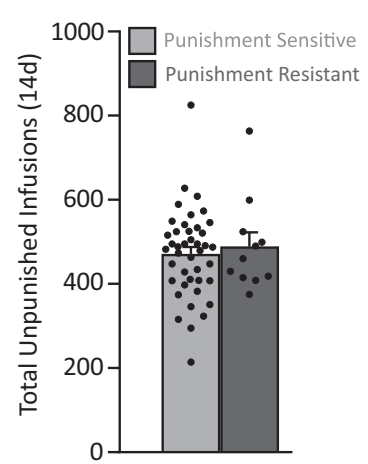

C) Distribution of Punishment Sensitivity

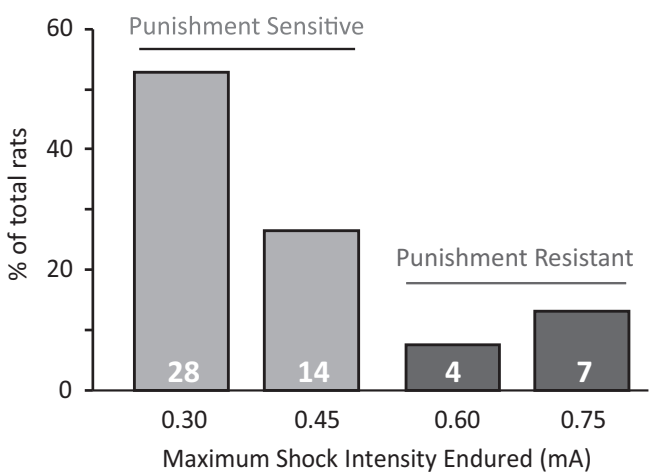

Punishment Sensitivity Unrelated

F) to Cocaine-Induced Locomotion

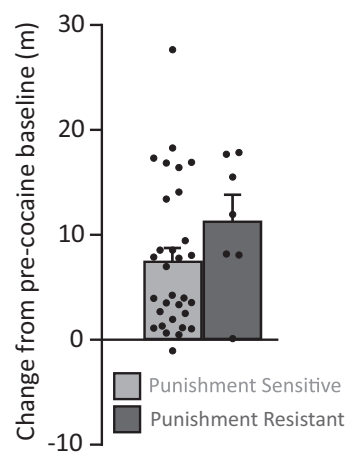

Fig. 2 Punishment-resistant rats are more prone than punishment-sensitive rats to cue-induced but not cocaine-primed relapse. a Probabilistic footshock reduces active lever pressing across all rats, while increasing the number of inactive presses. SA self-administration. b Individual variation in punishment sensitivity. Rats that reached at least $0.60 \mathrm{~mA}$ footshock were considered punishment resistant (dark/red shading). Punishment-sensitive rats (light/gray shading) stopped taking cocaine at $\geq 0.60 \mathrm{~mA}$ footshock intensities. c Most rats cease cocaine intake at low shock levels (punishment sensitive: dark/red shading): $42 / 53$ rats, $79.2 \%$ ), but a subset reached the highest shock levels (punishment resistant: dark/red shading): 11/53 rats, 20.8\%). d Punishment-resistant rats cue-reinstated more in the safe context, relative to punishment sensitive rats on vehicle day reinstatement tests (the same vehicle-day data are also depicted in Fig. 4). This effect was specific to cue-induced but not cocaine-primed relapse. e-f Punishment-resistant rats were no different than sensitive rats on unpunished cocaine intake (e) or cocaine-induced locomotion (f). ${ }^{* *} p<0.001$ 
Punishment context testing and training

Following safe context self-administration training, rats $(n=35)$ began punishment training in a distinct chamber, with different cues from those of the safe context. A VI30 schedule was still used, but $50 \%$ of cocaine infusions/cues were now accompanied by a $0.3 \mathrm{~mA}$ foot shock ( $0.5 \mathrm{~s})$. Although sex can impact sensitivity to footshock in other operant suppression models [75], shock intensity was not titrated here, and sex differences in suppression of cocaine intake were not observed (active lever presses change from baseline selfadministration: $t_{11}=0.095, p=0.92$ ). To test effects of inhibiting VP upon punished cocaine intake, a subset of rats were injected with either CNO $(n=22)$ or vehicle $(n=13)$ prior to each of the first two daily shock punishment training sessions. In a crossover design, these rats were administered the opposite treatment (vehicle/CNO) prior to a third punished intake session $48 \mathrm{~h}$ later, then additional punished cocaine intake training session with no vehicle or CNO injections was conducted. Another group of rats $(n=31)$ received no injections during punished training. After 3-4 days of shock training at $0.3 \mathrm{~mA}$, shock intensity was increased by $0.15 \mathrm{~mA}$ every 2 subsequent training days, up to $0.75 \mathrm{~mA}$, or until voluntary abstinence criterion was met by each rat $(<5$ active lever presses for 2 consecutive days).

\section{Punishment sensitivity classification}

Sensitivity to punishment was determined in two ways. A suppression ratio (infusions on day 1 punishment/infusions on last day unpunished; $[17,76])$ was calculated as a measure of initial punishment sensitivity, with high ratios reflecting relative insensitivity of cocaine intake to shock. Rats were classified as relatively punishment resistant or sensitive based on the maximum level of shock they tolerated before meeting abstinence criterion. Punishment-resistant rats were defined for analyses as those exceeding 5 active lever presses for 2 consecutive sessions at $0.45 \mathrm{~mA}$ footshock intensity, therefore requiring higher shock intensities (0.60-0.75 mA) to achieve voluntary abstinence (Fig. 2b). As previously reported [5, 71, 73], punishment-resistant rats underwent more shock training sessions (mean \pm SEM, 7.62 \pm 0.24) than punishment-sensitive rats (mean \pm SEM, $4.25 \pm 0.15$; $\left.t_{51}=11.16, p<0.0001\right)$. All rats eventually suppressed their intake to criterion levels by day 9 of punished training.

\section{Measuring mixed motivations during punished cocaine intake: "abortive lever pressing"}

During punished cocaine intake training sessions, rats displayed a previously characterized, species-typical risk assessment behavior "abortive lever pressing" [77-79], in which they stretch their trunk and extend their forepaw toward the active or inactive lever, but rapidly retract it without completing the press to deliver cocaine +chance of shock. Aborted presses of the active and inactive levers were quantified by blinded video analysis of the final day of safe context self-administration and the first day of punishment context self-administration (after VP inhibition or control).

Relapse tests

A series of 2-h reinstatement tests commenced $48 \mathrm{~h}$ after rats met abstinence criterion, with $48 \mathrm{~h}$ elapsing between each test, during which time rats remained in their home cages. Reinstatement tests occurred in: safe context with response-contingent cues $(n=$ 66; vehicle/CNO administered on separate consecutive test days, in counterbalanced order), then the safe context without cues (vehicle/CNO, $n=31$ ), safe context with a cocaine-priming injection $(10 \mathrm{mg} / \mathrm{kg}$; vehicle/CNO, $n=38)$, punishment context with cues (vehicle/CNO, $n=35$ ), and punishment context without cues (vehicle only, $n=24$; see Table S2 for reinstatement testing orders). Reinstatement testing order was chosen to limit carryover effects from previous reinstatement tests, e.g., by conducting cocaine-primed tests after cue tests to limit impact of noncontingent cocaine on conditioned responding $[80,81]$. Though expected extinction-related order effects on cocaine-free cue reinstatement tests were seen (first versus second reinstatement test: $\left.t_{65}=4.23, p<0.0001\right), \mathrm{CNO}$ and vehicle tests were counterbalanced within each reinstatement type, limiting the impact of test order on overall behavior [47, 81-85]. For reinstatement tests with response-contingent cues, active lever presses yielded cocaine-associated discrete cues (but no cocaine or shock), delivered on a VI30 schedule, each followed by a 15-s timeout period. For tests without discrete cues, lever presses were without consequence, but recorded.

\section{Cocaine-induced locomotion}

Following reinstatement tests, a subset of rats $(n=51)$ habituated to a locomotor testing chamber for 2 consecutive days, followed by two counterbalanced 2-h locomotor tests, $48 \mathrm{~h}$ apart. Next, rats were placed in the chamber for $30 \mathrm{~min}$ after vehicle/CNO, injected with cocaine, and then returned to the chamber for $90 \mathrm{~min}$. Horizontal distance traveled and the number of vertical rears were recorded via infrared beam breaks.

\section{Relapse-related Fos}

To examine VP neuronal activity during reinstatement, some rats underwent a final drug-free 2 -h reinstatement test, $48 \mathrm{~h}$ after their last vehicle/CNO reinstatement test. They were tested in: the safe context with cues $(n=15)$, safe context without cues $(n=16)$, punishment context without cues $(n=13)$, or no reinstatement (removed directly from their home cage after equivalent selfadministration/reinstatement training, $n=7$ ). To capture neural activity occurring during the entire 2 -h test, rats were returned to their home cages for $90 \mathrm{~min}$, then perfused with saline $(0.9 \%)$ and PFA (4\%; 210 min after the start of behavioral testing) [86]. Brains were then sectioned $(40 \mu \mathrm{m})$ following cryoprotection in $20 \%$ sucrose azide.

\section{Fos quantification}

To allow quantification of neural activity within anatomically defined VP subregions, we stained for Fos and substance $P$ to define VP borders. Ventromedial, ventrolateral, and dorsolateral subregions of substance P-defined VP were delineated with reference to adjacent sections stained for substance $P$ and neurotensin, defining ventromedial VP $[54,87]$. Dorsolateral VP and ventrolateral VP were defined by the relative absence of neurotensin immunoreactivity $[54,87]$. Images of VP were taken at $\times 5$ magnification, and one section/rat was quantified bilaterally in rostral VP $(+0.12$ to $+0.60 \mathrm{~mm}$ relative to Bregma), and another in caudal VP ( -0.48 to $-0.24 \mathrm{~mm}$; [88]), squarely within the rostral and caudal zones defined in our previous work [47]. Fos + neurons were identified using the Stereoinvestigator (Microbrightfield) particle counter tool, with thresholding parameters incorporating particle size $\left(>2\right.$ and $\left.<200 \mu \mathrm{m}^{2}\right)$, minimum distance between nuclei $(150 \mu \mathrm{m})$, and color relative to background. Fos density (Fos $/ \mathrm{mm}^{2}$ ) was computed for each VP subregion on each slice (average of both hemispheres) of each rat. All structure delineation and quantification was performed blind to experimental conditions, and imaging/analysis settings were consistent across rats.

Statistical analyses

Graphpad Prism software was used for statistical analyses. Effects of punishment on self-administration were examined with repeated-measures analyses of variance (ANOVAs), including day (last unpunished plus 3 initial punished days) and behavioral output (active lever, inactive lever, infusions) factors. Punishmentsensitive versus -resistant groups were compared on reinstatement using two-way ANOVA of punishment sensitivity group $\times$ reinstatement modality factors. Pearson correlation was used for assessing relationships between aborted lever presses and completed lever presses. Effects of punishment sensitivity group on unpunished cocaine intake and cocaine-induced locomotion were examined with unpaired $t$ tests. Effects of CNO in control and 
A)
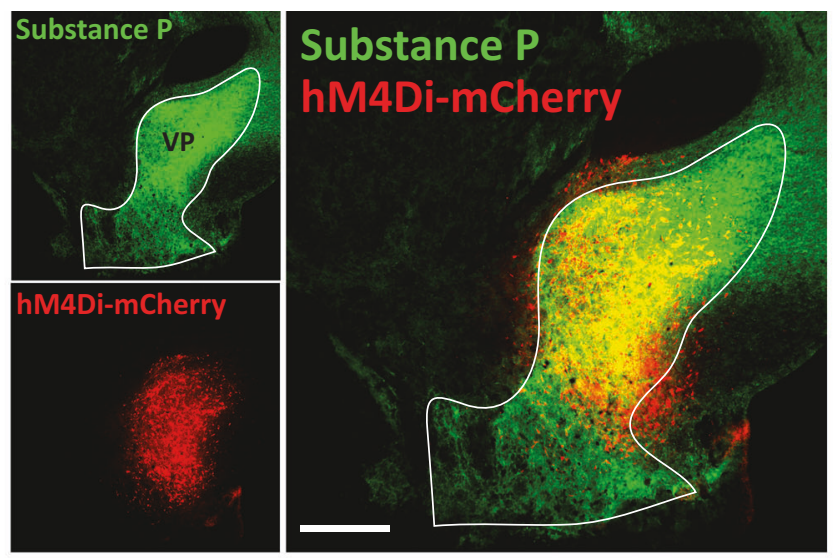

C)

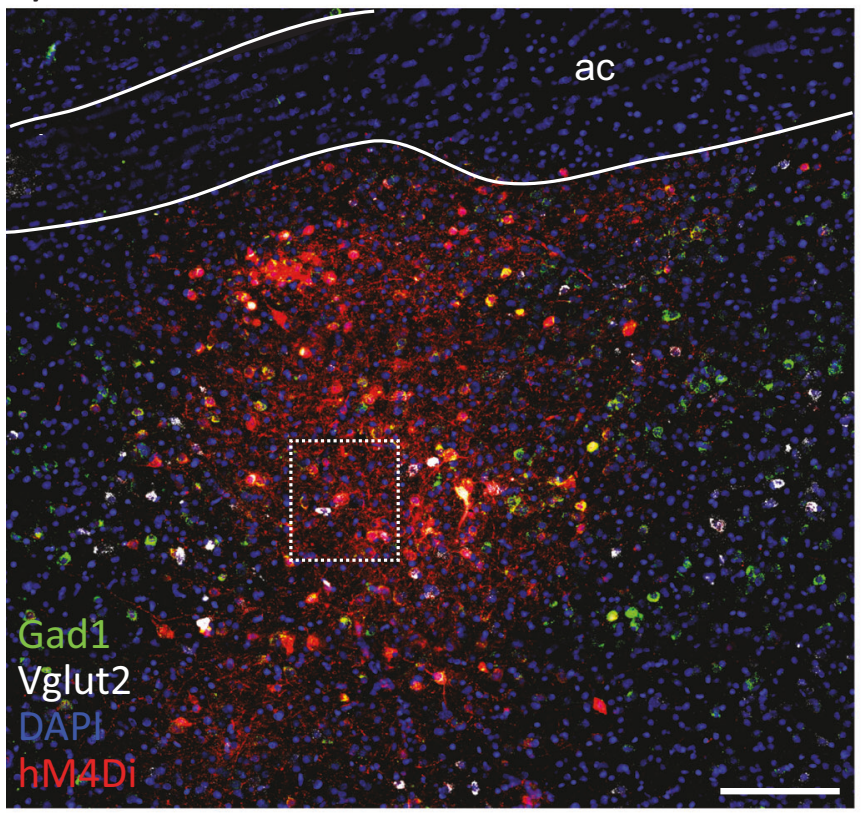

B)

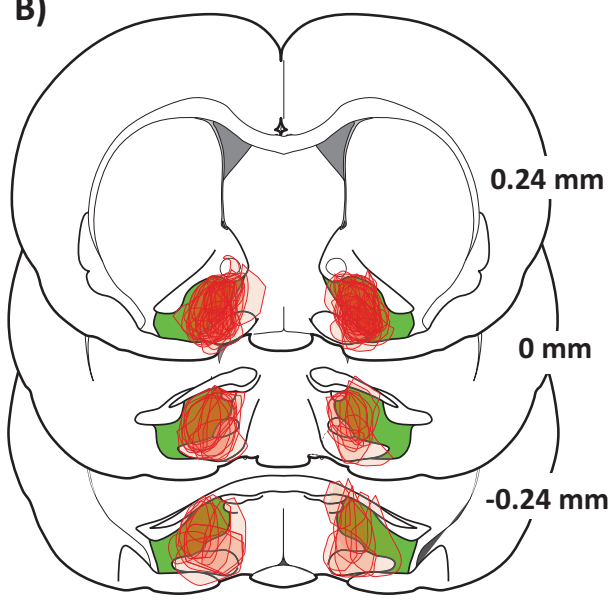

D)

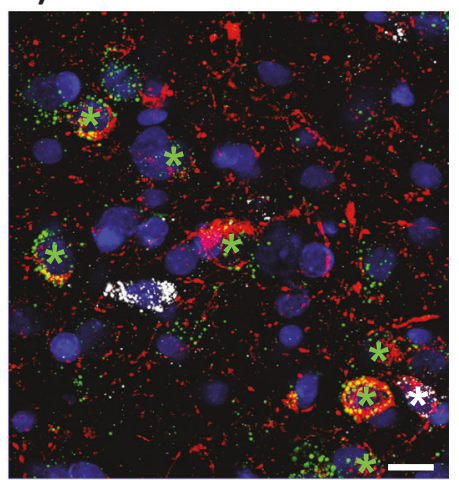

E)

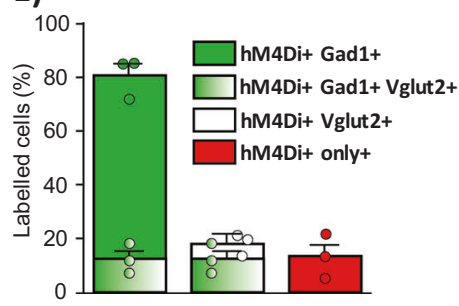

Fig. 3 Inhibitory DREADD localization in VP. a Immunofluorescent co-stain for hM4Di-mCherry (red) within substance P-expressing VP borders (green). b Bilateral hM4Di expression sites in individual animals on VP's rostrocaudal axis relative to bregma. c Wide-field and d highmagnification images of fluorescent in situ hybridization for Gad1 (green) and Vglut2 (white), combined with immunofluorescence for hM4DimCherry (red). $\mathrm{hM} 4 \mathrm{Di}^{+} / \mathrm{Gad} 1^{+}$cells are labeled with green stars, and $\mathrm{hM} 4 \mathrm{Di}{ }^{+} / \mathrm{Nglut}^{+}$cells are labeled with white stars. e $80.8 \pm 4.4 \%$ of $\mathrm{hM} \mathrm{Di}^{+}$cells are co-positive for Gad1 (green bar). $12.3 \pm 3.2 \%$ of hM4Di ${ }^{+}$cells are co-labeled for both Gad1 and Vglut2 (green gradient bar). $18.1 \pm 2.4 \%$ of $\mathrm{hM} \mathrm{Di}^{+}$cells are co-labeled for Vglut2 (white bar). $13.3 \pm 4.8 \%$ of $\mathrm{hM} 4 \mathrm{Di}^{+}$cells are negative for both Gad1 and Vglut2 (red bar)

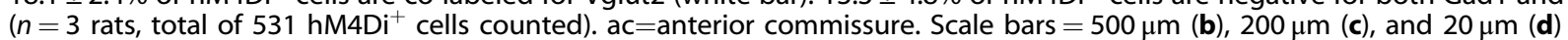

VP-hM4Di rats on abortive lever pressing were computed with one-way ANOVA. Effects of CNO versus vehicle on each reinstatement modality were examined using separate repeatedmeasures ANOVAs for VP-hM4Di and control rats, with drug (vehicle/CNO) and lever (active/inactive) factors. Effects of VP inhibition on reinstatement in punishment-resistant and -sensitive rats were computed as change from vehicle day behavior (CNO-vehicle) and analyzed with unpaired $t$ test. Separate oneway ANOVAs compared behavioral groups on Fos density in each VP subregion. Impact of rostrocaudal VP location on Fos was examined with a two-way ANOVA on rostral/caudal site and reinstatement modality factors. Separate two-way ANOVAs were used to compare CNO effects on cocaine-induced horizontal distance and rearing in control and VP-hM4Di rats. Tukey and Bonferroni corrected $t$ tests were used for post hoc comparisons as appropriate. Two-tailed tests with a significance threshold of $p<0.05$ were used for all analyses.

\section{RESULTS}

Unpunished self-administration

Rats readily discriminated between the inactive and active lever (lever: $\left.F_{(1,130)}=55.3, p<0.0001\right)$, and daily cocaine intake was stable by the final 3 days of training $\left(F_{(2,130)}=0.87, p=0.42\right.$; Fig. S2). Male and female rats did not differ in active lever presses or (sex-adjusted) cocaine doses self-administered during the last 3 days of training (no main effect of sex (lever: $F_{(1,64)}=1.8, p=0.19$, infusions: $\left.F_{(1,64)}=0.29, p=0.59\right)$ or day $\times$ sex interaction (lever: $F_{(2,128)}=1.0, p=0.37$, infusion: $F_{(2,128)}=0.48$, $p=0.62$ ). 


\section{A)}

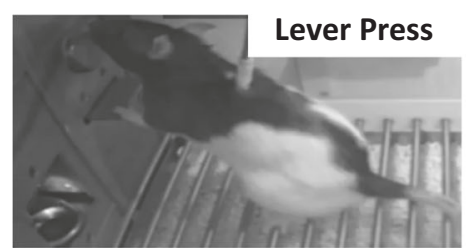

VP Inhibition Effects on Punished Cocaine Taking

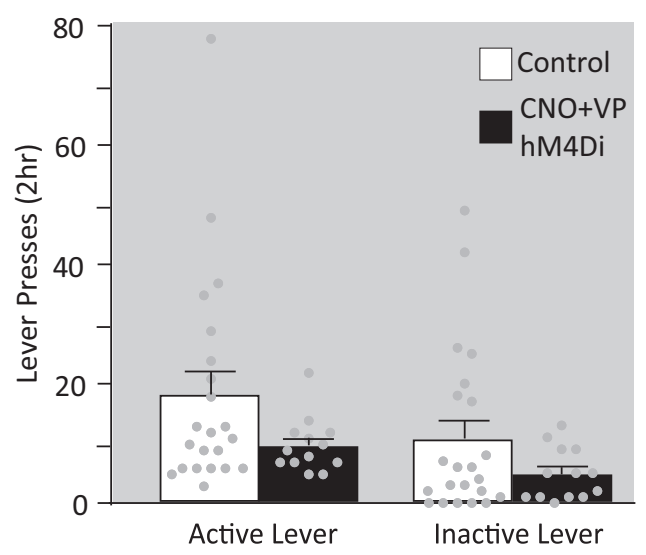

B)

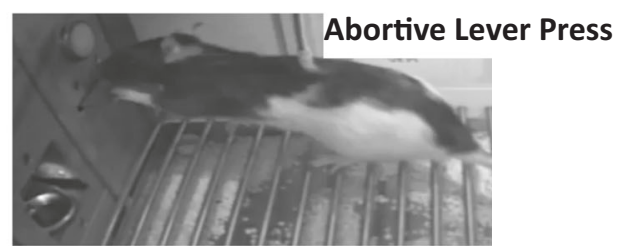

VP Inhibition Reduces Abortive Lever Presses During Punished Cocaine Taking

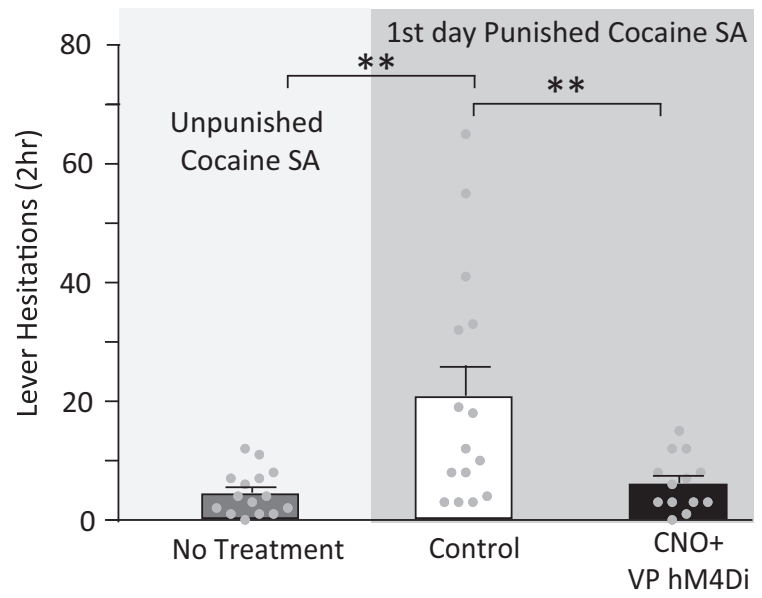

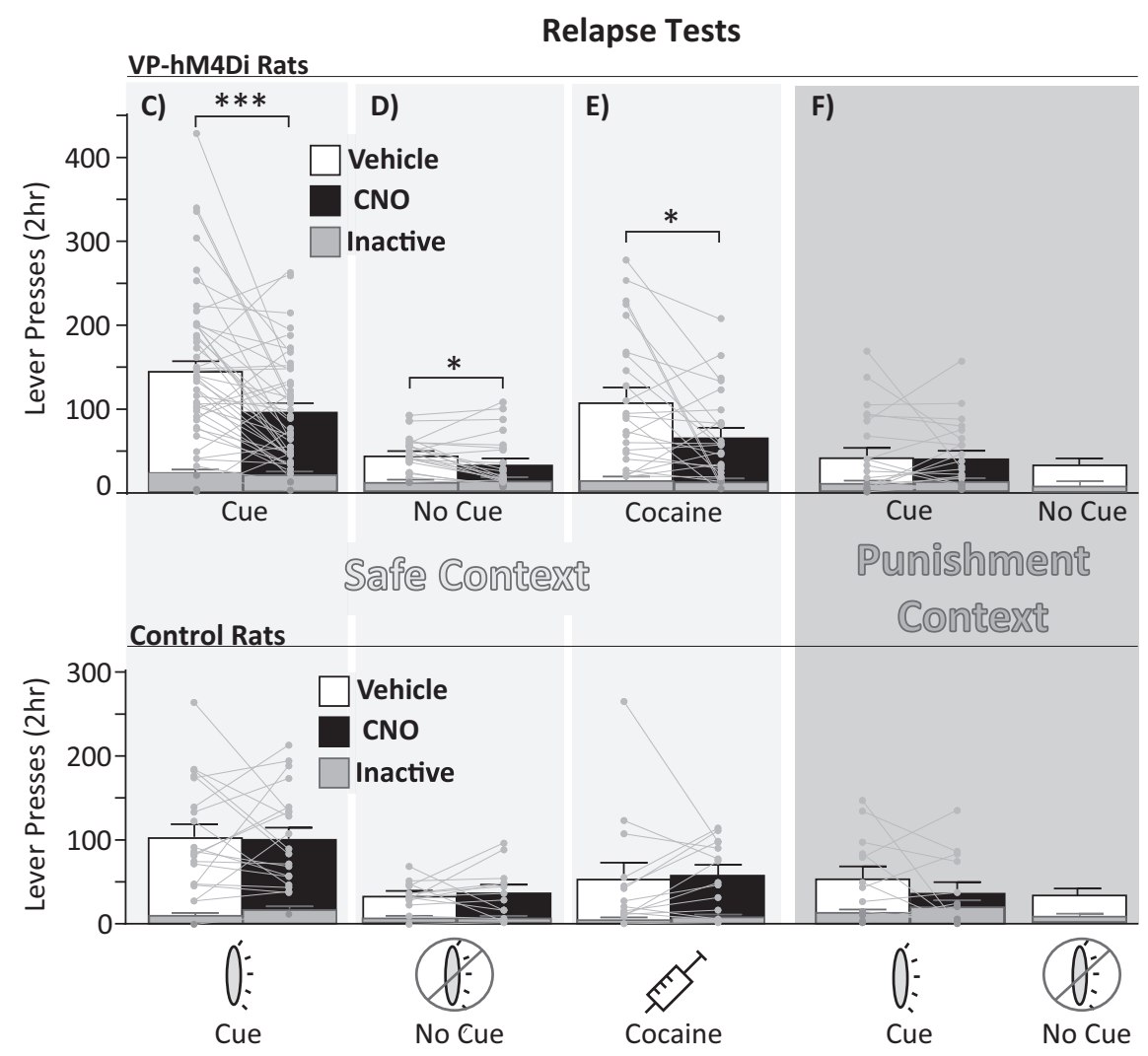

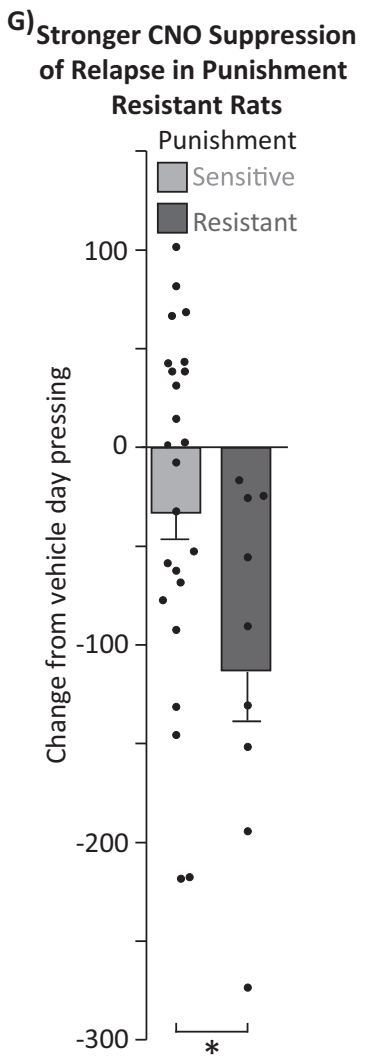

Individual differences in cocaine seeking under punishment As expected, cocaine-coincident shock (50\% of infusions) in the punishment context suppressed cocaine self-administration overall (day: $F_{(3,585)}=30.1, p<0.0001$, Fig. 2a). Most rats $(79.2 \%$; $n=42$ ) reached suppression criterion at the two lowest shock intensities (0.30-0.45 mA: "punishment sensitive" rats), but a subset of rats $(20.8 \%, n=11)$ persisted in responding up to higher shock intensities (0.60-0.75 mA: "punishment-resistant" rats; Fig. 2 b, c). In addition, punishment-resistant rats had higher suppression ratios (infusions on the first day in the punishment context/infusions on the last day in the safe context [17, 76]; mean $\pm S E M=0.48 \pm 0.09$ ) than punishment-sensitive rats 
Fig. 4 VP inhibition reduces relapse-like behavior, especially in punishment-resistant rats. a Top panel: Example picture of a completed lever press. Bottom panel: CNO in VP-hM4Di rats modestly reduces active and inactive lever pressing for cocaine under threat of punishment on day 1 of punishment training. Control = vehicle-injected rats and CNO-injected VP misses. b Top panel: Example of an aborted press, in which the rat stretches its trunk toward the lever and extends its paw, without depressing the lever. Bottom panel: Active and inactive abortive lever pressing, quantified during safe (light/green shading) and punished (dark/red shading) intake sessions. CNO in VP-hM4Di rats reduced abortive lever pressing relative to control rats, returning abortive pressing to unpunished self-administration levels. Control = vehicle-injected rats and CNO-injected VP misses. c-f Within-subject comparisons of reinstatement for VP-hM4Di rats (top panels) in safe (light/green shading) and punishment (dark/red shading) contexts. CNO in VP-hM4Di rats reduced reinstatement in the safe context with cues (c), without cues (d), and with cocaine and no cues (e) but not in the punishment context with cues (f). CNO in control rats did not affect reinstatement under any condition (bottom panels). Control = eGFP-only rats and rats with hM4Di expression primarily outside VP. g CNO in VP-hM4Di punishmentresistant rats (dark/red bars) elicited a greater decrease in cued reinstatement, relative to VP inhibition in punishment-sensitive rats (light/gray bars). Data presented as change from vehicle test baseline. ${ }^{*} p<0.05,{ }^{* *} p<0.01,{ }^{* * *} p<0.001$

(mean $\pm \mathrm{SEM}=0.25 \pm 0.02 ; t_{64}=4.4, p<0.0001$ ). Notably, of the 11 punishment-resistant rats in this study, 7 were female $(30.4 \%$ of tested females), while 4 were male (13.3\% of tested males).

\section{Punishment-resistant rats reinstated more}

Punishment-resistant rats, once they received shock intensities high enough to suppress even their seeking, showed greater cueinduced reinstatement than punishment-sensitive rats. However, this was only true when response contingent cues were delivered, and not for cocaine-primed reinstatement (punishment sensitivity $\times$ reinstatement type interaction: $F_{(1,87)}=2.92, p=0.091$; Bonferroni corrected $t$ test, punishment resistant versus sensitive in safe context with cues: $t_{87}=3.43, p=0.0019$; Fig. $2 d$; note: Fig. $2 d$ shows vehicle-day reinstatement data). Punishment resistance was unrelated to total prior cocaine self-administered (punishment-resistant versus -sensitive total unpunished infusions: $t_{51}=$ $0.51, p=0.61$; Fig. 2e) or to cocaine's locomotor-stimulating or relapse-promoting effects (horizontal distance traveled: $t_{36}=1.34$, $p=0.19$; Fig. 2f; rearing: $t_{36}=1.69, p=0.10$; cocaine-primed reinstatement active lever presses: $t_{36}=0.83, p=0.41$ ), indicating that punishment resistance and cue-induced relapse likely involve common underlying individual differences in addictionlike compulsivity rather than sensitivity to cocaine's effects per se.

DREADD expression in VP neuronal populations

Robust hM4Di-DREADD expression was observed throughout the rostrocaudal extent of VP (Fig. 3a, b). Fluorescent in situ hybridization (RNAscope) revealed a predominant colocalization of hM4Di expression with Gad1 (80.8 $\pm 4.4 \%$ of hM4Di ${ }^{+}$cells), and a smaller percentage colocalizing with Vglut2 $(18.1 \pm 2.4 \%$ of $\mathrm{hM} \mathrm{Di}^{+}$cells; Fig. 3c-e). A small fraction of the cells expressed both transcripts $\left(12.3 \pm 3.2 \%\right.$ of $\mathrm{hM} \mathrm{Di}^{+}$cells). We note that colocalization of Gad1 and Vglut2 transcripts is not sufficient to establish the co-release of glutamate and GABA by these neurons, especially since the Vglut2 signal was weak compared to the Gad1 signal. hM4Di+ neurons lacking either Gad1 or Vglut2 $(13.3 \pm 4.8 \%$, Fig. 3e) may represent cholinergic neurons $[31,54]$. These DREADD expression results are consistent with unbiased transduction of all VP neurons, as GABA neurons represent the predominant neuronal phenotype in VP [31].

\section{CNO effects on punishment-induced suppression of cocaine} intake in VP-hM4Di rats

On day 1 of punished self-administration, CNO in VP-hM4Di rats modestly, but non-significantly, decreased the number of active and inactive lever presses relative to control rats (treatment: $F_{(1,33)}=3.41, p=0.073$; Fig. 4a), with no interaction of treatment $\times$ lever $\left(F_{(1,33)}=0.27, p=0.61\right)$. CNO had no further effects on lever pressing on day 2 , though all rats decreased their responding relative to day 1 (day: $F_{(1,33)}=20.56, p<0.0001$ ), indicating a likely floor effect due to prior punishment training. When vehicle and CNO treatments were reversed on punishment day 3, no further changes were observed ( $p s>0.05$ ).
Footshock+cocaine also increased abortive pressing of the active and inactive levers, relative to the low levels of abortive pressing seen during unpunished self-administration in the safe context $\left(F_{(2,40)}=7.93, p=0.0013\right.$; self-administration versus vehicle day punishment: $p=0.0022$; Fig. 4b). Aborted lever presses were most prevalent in rats with the most punished active lever presses (correlation of aborted lever presses and completed presses after both CNO; $r=0.61, p=0.027$; and vehicle; $r=0.61, p$ $=0.016$ ), suggesting that abortive lever pressing may be a sensitive measure of deliberation about pursuing the nowdangerous cocaine. Interestingly, CNO strongly suppressed aborted lever presses, returning them to unpunished levels in VP-hM4Di rats $(p=0.0013$; Tukey test, CNO versus self-administration: $p=0.93$ ) but not in controls (controls versus selfadministration: $p=0.0082$; Fig. $4 \mathrm{~b}$ ).

VP DREADD inhibition suppresses cocaine relapse after voluntary abstinence

CNO in VP-hM4Di rats robustly suppressed context only-, cue-, and cocaine-induced relapse in the safe context but failed to do so in control rats without VP DREADDs. In VP-hM4Di rats, CNO (compared to vehicle) reduced cue-induced active but not inactive lever pressing in the safe context (drug $\times$ lever interaction: $F_{(1,45)}=18.53, p<0.0001$; Fig. 4c). VP-hM4Di rats with the most specific DREADD localization ( $>60 \%$ in VP; $n=13$ ) exhibited stronger decreases in cue-induced reinstatement relative to rats with less specific DREADD localization $(40-60 \%$ in VP; $n=33$; $\left.t_{44}=2.01, p=0.05\right)$, suggesting that behavioral effects are primarily due to VP inhibition rather than inhibition of nearby structures. Moreover, CNO failed to alter cue-induced reinstatement in rats with selective DREADD expression in the VP-adjacent horizontal limb of the diagonal band (HLDB; $n=5)$, a region that was usually partially penetrated in VP-hM4Di rats (no effect of treatment: $F_{(1,4)}=0.47, p=0.53$; or treatment $\times$ lever interaction: $\left.F_{(1,4)}=0.47, p=0.53\right)$.

CNO administration in VP-hM4Di rats suppressed safe context pressing without response-contingent cues (drug $\times$ lever interaction: $F_{(1,20)}=4.31, p=0.05$; Fig. $4 d$ ). Cocaine-primed reinstatement (no cues) in the safe context was also suppressed by CNO in VPhM4Di rats (drug $\times$ lever interaction: $F_{(1,23)}=7.94, p=0.01$; Fig. $4 \mathrm{e}$ ). Effects of VP inhibition on cocaine-primed reinstatement in the punishment context were not examined here but warrant future study. Although we previously showed that rostral and caudal VP differentially mediate cue and primed reinstatement using a spread-limiting lentiviral vector [47], AAV2 viral infection here spanned most of the rostrocaudal axis of VP. In contrast to the safe context, CNO in VP-hM4Di rats failed to reduce cue reinstatement in the punishment context (drug $\times$ lever interaction: $F_{(1,21)}=0.19$, $p=0.66$; Fig. 4f). This null finding was unlikely to have resulted from a floor effect, since pressing was similar in the punishment context with cues and the safe context without cues, yet VP inhibition suppressed only the latter. In control rats without VP DREADDs, CNO had no effects on lever pressing in any reinstatement test ( $p s>0.05$; Fig. $4 c-f$ ), suggesting that CNO 
A)

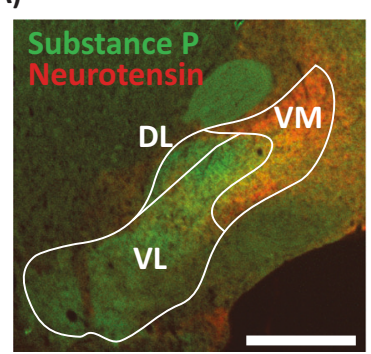

B)

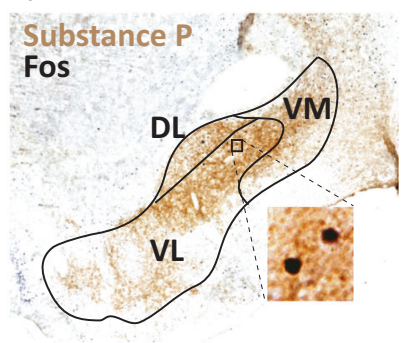

C)
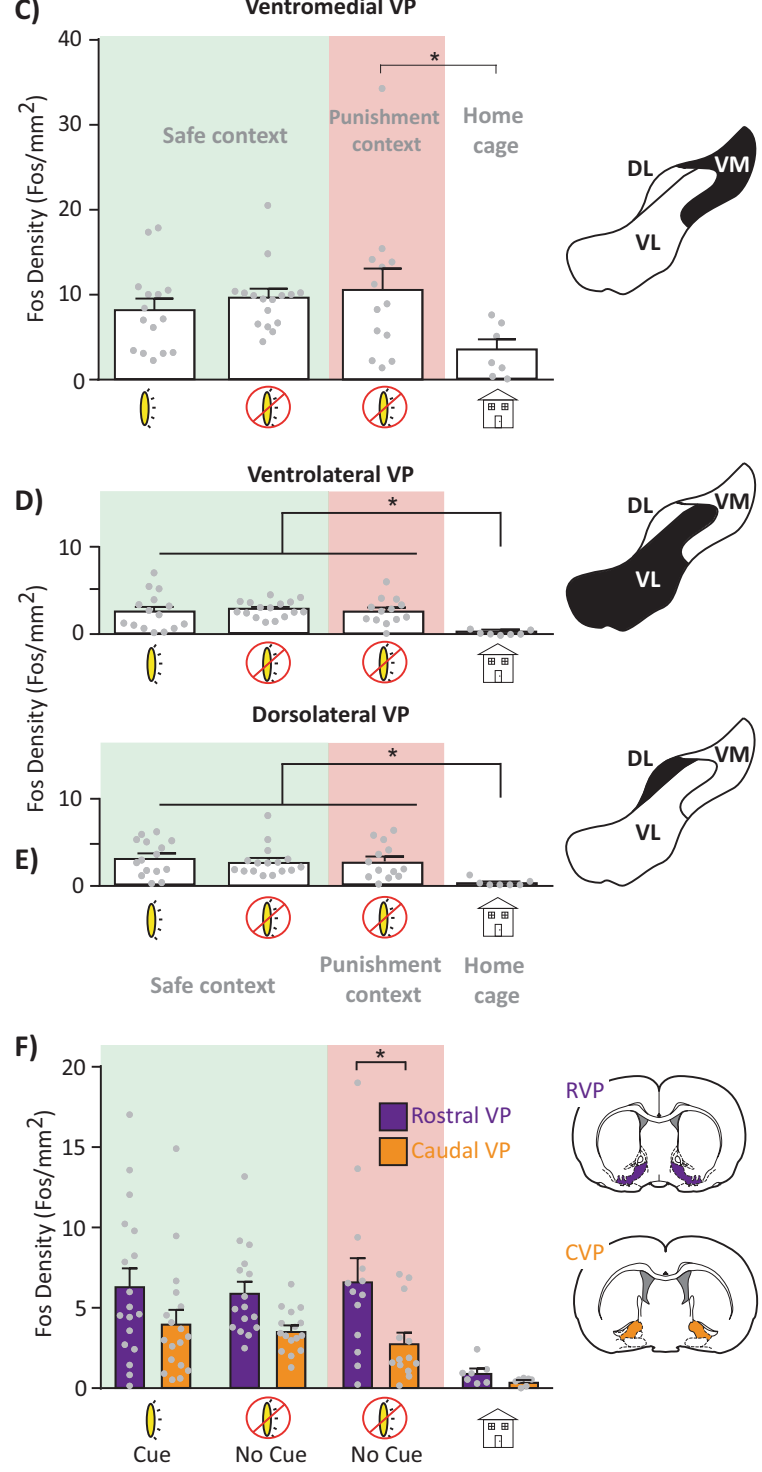

Fig. 5 VP subregion Fos expression after relapse-like behavior. a Representative image of substance P (VP borders) and neurotensin (ventromedial VP marker) immunofluorescent co-stain. b Representative image of substance $\mathrm{P}$ and Fos co-staining used for Fos quantification. c-e Comparison of VP ventromedial (c), ventrolateral (d), and dorsolateral (e) Fos density across reinstatement conditions. Light/green shading = safe context, dark/red shading = punishment context, no shading = home cage controls. $f$ Fos density across the VP rostrocaudal axis after reinstatement tests (collapsed across mediolateral subdivisions). Rostral VP (purple/dark bars) had greater Fos density than caudal VP (orange/light bars) only in the punishment context+no cues condition; VM ventromedial, VL ventrolateral, DL dorsolateral. AC anterior commissure. Scale bar $=1000 \mu \mathrm{m}$. ${ }^{*} p<0.05$ effects here, as previously shown $[45,47,81,89]$, were specific to VP inhibition.

VP inhibition suppressed relapse most in punishment-resistant rats

VP inhibition reduced safe context cue-induced reinstatement more in punishment-resistant rats than in punishment-sensitive rats $\left(t_{44}=2.23, p=0.031\right.$; Fig. $\left.4 \mathrm{~g}\right)$. This effect was specific to the safe context with cues, as there was no such effect on other reinstatement types ( $t$ values $<1.26$, $p s>0.22$ ). Importantly, DREADD expression was identical in punishment-sensitive and -resistant groups (percentage of VP infected: $t_{31}=1.16 ; p=0.25$; percentage of expression within VP borders: $t_{31}=0.85, p=0.40$ ). This finding suggests that VP plays an especially important role in relapse after punishment-imposed abstinence for the individual rats showing the most addiction-like behavior.

VP inhibition did not affect cocaine-induced locomotion CNO failed to affect the locomotor-activating effects of cocaine in either the VP-hM4Di or control groups (treatment: $F_{(1,49)}=0.63$, $p=0.43$; treatment $\times$ group interaction: $F_{(1,49)}=0.58, p=0.45$; Fig. S2A), though it did reduce rearing behavior after cocaine in VP-hM4Di rats but not in controls (treatment $\times$ group interaction: $F_{(1.49)}=10.24, p=0.0024$; Fig. S2B). Moreover, CNO did not differentially reduce horizontal locomotion or rearing in punishment-sensitive versus -resistant VP-hM4Di rats (group $\times$ treatment interaction; locomotion: $F_{(3,93)}=0.70, p=0.55$; rearing: $\left.F_{(3,93)}=0.61, p=0.61\right)$. These results indicate that VP mediates cocaine-induced motivation but not all cocaine-induced behaviors.

VP subregion Fos recruited during relapse

Relative to cocaine/shock-experienced rats sacrificed from their homecages, VP subregions showed strong Fos activation during all tested reinstatement conditions $\left(F_{(3,47)}=3.93, p=0.014\right.$; Tukey: punishment + no cues, $p=0.013$; safe + cues, $p=0.019$; safe + no cues, $p=0.043)$. Ventromedial VP was selectively activated (relative to home cage) by the punishment context without cues but not by either of the safe context reinstatement tests $\left(F_{(3,47)}=\right.$ 2.67, $p=0.05$; Tukey: punishment +no cues: $p=0.048$; safe+cues: $p=0.28$; safe + no cues: $p=0.09$; Fig. $5 a-c)$. In contrast, ventrolateral and dorsolateral VP were activated in all reinstatement conditions, relative to homecage controls (ventrolateral: $F_{(3,47)}=$ 5.98, $p=0.0015$; Tukey: safe+cues: $p=0.0051$; safe + no cues: $p=$ 0.0011 ; punishment + no cues: $p=0.0049$; Fig. $5 \mathrm{~d}$; dorsolateral: $F_{(3,47)}=4.63, p=0.006$; Tukey: safe+cues: $p=0.0043$; safe + no cues: $p=0.017$; punishment + no cues: $p=0.021$; Fig. $5 \mathrm{e}$ ). We then examined Fos expression based on rostral and caudal section positions within VP, given known rostrocaudal functional and anatomical differences [47, 54-56]. Overall, rostral VP had greater Fos density than caudal VP $\left(F_{(3,47)}=4.8, p=0.0051\right)$, though this did not significantly differ between reinstatement types (no reinstatement type $\times$ rostrocaudal position interaction; $F_{(3,47)}=$ $1.42, p=0.25$; Fig. 5f).

Sex differences

Few sex differences in VP manipulation effects were detected. Male and female rats exhibited comparable levels of punishmentinduced suppression of cocaine self-administration (suppression ratio: $t_{64}=1.65, p=0.10$ ) and comparable levels of cocaine selfadministration (Fig. S3A). Notably, female rats represent $63.6 \%$ of the punishment-resistant rats (7/11 rats), while females represent $38.1 \%$ of the punishment-sensitive rats (16/42 rats; Fig. S3B). As previously reported [90], females exhibited more cocaine-induced locomotion than males (sex; $F_{(1,31)}=4.91, p=0.034$ ), though CNO in VP-hM4Di rats did not sex-dependently impact locomotion (sex $\times$ treatment interaction; $F_{(1,31)}=0.33, p=0.57$ ) or any type of reinstatement $(F s<2.5, p s>0.13$; Fig. $S 3 C-F)$. Despite greater 
cocaine-induced locomotion in females, no sex differences in cocaine-primed reinstatement were seen $\left(F_{(1,22)}=2.06, p=0.17\right)$, suggesting that cocaine's arousing and incentive motivational effects are differentially impacted by sex.

\section{DISCUSSION}

These findings point to a crucial role for VP in cocaine relapse following voluntary abstinence, a translationally relevant model of humans who relapse after quitting drugs due to mounting negative life outcomes. Indeed, we found that VP plays an especially important role in the most compulsive cocaine-seeking individuals, i.e., the $\sim 20 \%$ of rats that here tolerated significant footshock punishment to continue taking cocaine. We also found robust relapse-related activity in anatomically defined VP subregions. Our results suggest that, unlike connected limbic nuclei, VP plays a critical role in reinstatement regardless of how abstinence was achieved or how relapse was initiated, thereby placing it among the most essential nodes within the neural circuits of cocaine addiction.

VP is essential for addiction-like compulsive seeking and relapse Persistent drug use despite negative consequences and longlasting relapse propensity are cardinal features of addiction in humans [91]. Though compulsive drug intake despite punishment is common following extended drug access in rodents $[22,23,76]$, some rats seem to transition to compulsive use even after short access to cocaine. Here we observed such a subset of compulsive rats, and found that these same animals were also most sensitive to cue+context reinstatement after voluntary abstinence, similar to prior findings $[17,25,29]$. Importantly, VP inhibition in these compulsive rats had a greater relapse-suppressing effect than in punishment-sensitive rats, suggesting that VP plays a particularly important role in those rats that most pathologically seek drug. VP inhibition only modestly reduced punished cocaine selfadministration but selectively reduced abortive pressing of the cocaine/shock and inactive levers, which we interpret as reflecting motivation to pursue cocaine tempered by motivation to avoid being shocked. These results highlight the sensitivity of this novel assay of conflicting motivations during cocaine seeking, as well as the importance of careful ethological analysis of complex drugseeking behaviors during such neural circuit manipulation experiments.

Relapse is not a unitary phenomenon, since brain circuits underlying drug reinstatement depend on the drug of choice, mode of abstinence, and relapse trigger [10-12, 26, 92-95]. This said, we show that even under maximally human-relevant conditions VP is broadly implicated in reinstatement regardless of trigger or mode of abstinence. In contrast, other VP-connected limbic regions seem to be engaged differentially during reinstatement after different modes of abstinence. For example, inhibition of basolateral amygdala decreases reinstatement after extinction training, whereas the same manipulation during reinstatement following punishment-induced abstinence increases drug seeking [10]. These results are consistent with the idea that VP serves as a "final common pathway" of drug seeking $[38,39]$. Therefore, VP holds promise as a potential therapeutic target for suppressing relapse in humans, especially since a prior human functional magnetic resonance imaging report found that activity in the vicinity of VP predicts relapse propensity in humans [96].

Interestingly, in the unpunished safe context, VP inhibition attenuated reinstatement with or without cues and also cocaineprimed reinstatement, yet VP inhibition did not reduce cue reinstatement in the punishment context. As expected, conditioned suppression of cue-induced seeking was observed in the punishment context relative to the safe context, but responsecontingent cues nonetheless supported some pressing, and this was not affected by VP inhibition (Fig. 4). We therefore speculate that VP promotes conditioned drug seeking in a context-gated manner [97], consistent with prior reports that VP is necessary for context-induced reinstatement of alcohol seeking [44, 45, 49, 98].

\section{Heterogeneities in VP circuits underlying relapse}

$V P$ is a heterogeneous structure, with rostrocaudally and mediolaterally located subregions, and genetically distinct, functionally opposing neuronal subpopulations [30-32, 54, 61, 98]. We observed broad recruitment of Fos in VP subregions after exposure to both the safe and punishment contexts, and in the safe context when response-contingent cues were presented. This homecage-relative Fos recruitment was more pronounced in rostral than in caudal VP, yet there was broad activation of ventromedial, dorsolateral, and ventrolateral subregions under all reinstatement conditions. We note that VP DREADD expression here spanned rostrocaudal VP subregions, potentially obscuring the distinct roles these subregions may play in cocaine seeking [47]. Though we found no effect of selective inhibition of a VPadjacent region (HLDB) and reinstatement suppression effects were strongest in the rats with the most selective VP DREADD expression, the dissociable roles of VP subregions and of other nearby basal forebrain structures (e.g., lateral preoptic area) should be further investigated.

Our results suggest a global recruitment of VP subregions during safe context and safe context+cue-induced relapse and also during mere exposure to the punished context, though global VP inhibition failed to suppress cue-induced cocaine seeking in this dangerous context. One possible explanation for this puzzling pattern of effects is that functionally opposed VP cells are engaged in the safe and punished contexts, such as the intermingled VP GABA and glutamate neurons that drive appetitive and aversive behavior, respectively [30-32, 62, 63]. Our pan-neuronal chemogenetic approach primarily targeted reward-related VP GABA neurons ( $80 \%)$, which likely mediate reinstatement in the safe context, when aversion-related glutamate neuron activity may be less relevant. We speculate that, in the punishment context, glutamate and GABA neurons are both recruited (explaining Fos results), but inhibiting both populations concurrently with DREADDs suppressed motivation as well as aversion, resulting in a null effect. More work is clearly needed to parse the specific behavioral roles for VP subregions and neuronal subpopulations in addiction-related behaviors.

The circuit mechanisms by which VP inhibition reduces reinstatement remain puzzling, given that VP's strongest afferent is from NAc GABA neurons, in which neural activity would be expected to inhibit VP cells-yet this activity appears to promote motivation similarly to activity in VP itself [99-105]. Clearly, there is more complexity to the network-level interactions of VP and NAC than is currently appreciated. Future work should explore the motivation-related roles of NAc/NP subregional communication, functional distinctions between VP and/or NAc cell subpopulations, and also the major reciprocal projection from VP back to NAc $[42,55,59,106-108]$.

\section{CONCLUSION}

The present report firmly establishes VP as an essential node in the neural circuits of translationally relevant cocaine reinstatement behavior, especially in the most compulsive, addicted-like rats. By better understanding how addiction-relevant behaviors map onto defined neural circuits in the addicted brain, we may reveal neural signatures that could facilitate diagnosis and treatment of addiction in a personalized manner. These results join others which suggest that VP plays a pivotal role in relapse, spanning specific relapse triggers and modes of abstinence, making it a promising target for future interventions to treat addiction. 


\section{FUNDING AND DISCLOSURE}

This work was supported by PHS grants: R00DA035251, F31DA048578, P50DA044118, R25GM055246, T32NS045540, and $\mathrm{R} 21 \mathrm{MH} 118748$. The authors declare no competing interests.

\section{ACKNOWLEDGEMENTS}

We thank Yavin Shaham and Nathan Marchant for providing MED-PC code for punishment-induced abstinence and reinstatement protocols. We thank lohanna Pagnoncelli and Stephanie Lenogue for their assistance with behavioral testing.

\section{ADDITIONAL INFORMATION}

Supplementary Information accompanies this paper at (https://doi.org/10.1038/ s41386-019-0507-4)

Publisher's note Springer Nature remains neutral with regard to jurisdictional claims in published maps and institutional affiliations.

\section{REFERENCES}

1. Hunt WA, Barnett LW, Branch LG. Relapse rates in addiction programs. J Clin Psychol. 1971;27:455-6.

2. Wikler A. Dynamics of drug dependence: implications of a conditioning theory for research and treatment. Arch Gen psychiatry. 1973;28:611-6.

3. O'Brien CP, Childress AR, McLellan AT, Ehrman R. Classical conditioning in drugdependent humans. Ann NY Acad Sci. 1992;654:400-15.

4. Shaham Y, Shalev U, Lu L, de Wit H, Stewart J. The reinstatement model of drug relapse: history, methodology and major findings. Psychopharmacology. 2003;168:3-20.

5. Marchant NJ, Khuc TN, Pickens CL, Bonci A, Shaham Y. Context-induced relapse to alcohol seeking after punishment in a rat model. Biol Psychiatry. 2013;73:256-62.

6. Panlilio LV, Thorndike EB, Schindler CW. Reinstatement of punishmentsuppressed opioid self-administration in rats: an alternative model of relapse to drug abuse. Psychopharmacology. 2003;168:229-35.

7. Marchant NJ, Li X, Shaham Y. Recent developments in animal models of drug relapse. Curr Opin Neurobiol. 2013;23:675-83.

8. Economidou D, Pelloux Y, Robbins TW, Dalley JW, Everitt BJ. High impulsivity predicts relapse to cocaine-seeking after punishment-induced abstinence. Biol Psychiatry. 2009;65:851-6.

9. Venniro $M$, Caprioli $D$, Shaham Y. Animal models of drug relapse and craving: from drug priming-induced reinstatement to incubation of craving after voluntary abstinence. Prog Brain Res. 2016;224:25-52.

10. Pelloux Y, Minier-Toribio A, Hoots JK, Bossert JM, Shaham Y. Opposite effects of basolateral amygdala inactivation on context-induced relapse to cocaine seeking after extinction versus punishment. J Neurosci. 2018;38:51-9.

11. Fuchs RA, Branham RK, See RE. Different neural substrates mediate cocaine seeking after abstinence versus extinction training: a critical role for the dorsolateral caudate-putamen. J Neurosci. 2006;26:3584-8.

12. Marchant NJ, Campbell EJ, Pelloux Y, Bossert JM, Shaham Y. Context-induced relapse after extinction versus punishment: similarities and differences. Psychopharmacology (Berl). 2018;236:439-48.

13. Venniro $M$, Caprioli $D$, Zhang $M$, Whitaker LR, Zhang S, Warren BL, et al. The anterior insular cortex $\rightarrow$ central amygdala glutamatergic pathway is critical to relapse after contingency management. Neuron. 2017;96:414-27.

14. Venniro M, Zhang M, Caprioli D, Hoots JK, Golden SA, Heins C, et al. Volitional social interaction prevents drug addiction in rat models. Nat Neurosci. 2018;21:1520.

15. Golden SA, Jin M, Shaham Y. Animal models of (or for) aggression reward, addiction, and relapse: behavior and circuits. J Neurosci. 2019;39:3996-4008.

16. Belin D, Balado E, Piazza PV, Deroche-Gamonet V. Pattern of intake and drug craving predict the development of cocaine addiction-like behavior in rats. Biol Psychiatry. 2009;65:863-8.

17. Deroche-Gamonet V, Belin D, Piazza PV. Evidence for addiction-like behavior in the rat. Science. 2004;305:1014-7.

18. Vanderschuren LJMJ, Minnaard AM, Smeets JAS, Lesscher HMB. Punishment models of addictive behavior. Curr Opin Behav Sci. 2017;13:77-84.

19. Smith RJ, Laiks LS. Behavioral and neural mechanisms underlying habitual and compulsive drug seeking. Prog Neuropsychopharmacol Biol Psychiatry. 2018;87:11-21.

20. Pelloux Y, Hoots JK, Cifani C, Adhikary S, Martin J, Minier-Toribio A, et al. Context-induced relapse to cocaine seeking after punishment-imposed abstinence is associated with activation of cortical and subcortical brain regions. Addiction Biol. 2018;23:699-712.
21. Everitt BJ, Belin D, Economidou, Pelloux Y, Dalley JW, Robbins TW. Neural mechanisms underlying the vulnerability to develop compulsive drugseeking habits and addiction. Philos Trans $\mathrm{R}$ Soc Lond B Biol Sci. 2008:363:3125-35.

22. Vanderschuren LJMJ, Everitt BJ. Drug seeking becomes compulsive after prolonged cocaine self-administration. Science. 2004;305:1017-9.

23. Chen BT, Yau HJ, Hatch C, Kusumoto-Yoshida I, Cho SL, Hopf FW, et al. Rescuing cocaine-induced prefrontal cortex hypoactivity prevents compulsive cocaine seeking. Nature. 2013;496:359.

24. Anthony JC, Warner LA, Kessler RC. Comparative epidemiology of dependence on tobacco, alcohol, controlled substances, and inhalants: basic findings from the National Comorbidity Survey. Exp Clin Psychopharmacol. 1994;2:244.

25. Torres OV, Jayanthi S, Ladenheim B, McCoy MT, Krasnova IN, Cadet JL. Compulsive methamphetamine taking under punishment is associated with greater cue-induced drug seeking in rats. Behav Brain Res. 2017;326:265-71.

26. Farrell MR, Schoch H, Mahler SV. Modeling cocaine relapse in rodents: Behavioral considerations and circuit mechanisms. Prog Neuropsychopharmacol Biol Psychiatry. 2018;87(Pt A):33-47.

27. Bock R, Shin JH, Kaplan AR, Dobi A, Markey A, Kramer PF, et al. Strengthening the accumbal indirect pathway promotes resilience to compulsive cocaine use. Nat Neurosci. 2013;16:632.

28. Ersche KD, Barnes A, Jones PS, Morein-Zamir S, Robbins TW, Bullmore ET. Abnormal structure of frontostriatal brain systems is associated with aspects of impulsivity and compulsivity in cocaine dependence. Brain. 2011;134:2013-24.

29. Yager LM, Garcia AF, Donckels EA, Ferguson SM. Chemogenetic inhibition of direct pathway striatal neurons normalizes pathological, cue-induced reinstatement of drug-seeking in rats. Addiction Biol. 2019;24:251-64.

30. Stephenson-Jones $M$, Bravo-Rivera $C$, Ahrens S, Furlan A, Fernandes-Henriques C, Li B. Opposing contributions of GABAergic and glutamatergic ventral pallidal neurons to motivational behaviours. bioRxiv. 2019. https://doi.org/10.1101/ 594887.

31. Faget L, Zell V, Soyter E, McPherson A, Ressler R, Gutierrez-Reed N, et al. Opponent control of behavioral reinforcement by inhibitory and excitatory projections from the ventral pallidum. Nat Commun. 2018;9:849.

32. Tooley J, Marconi L, Alipio JB, Matikainen-Ankney B, Georgiou P, Kravitz AV, et al Glutamatergic ventral pallidal neurons modulate activity of the habenula-tegmental circuitry and constrain reward seeking. Biol Psychiatry. 2018;83:1012-23.

33. Saga Y, Richard A, Sgambato-Faure V, Hoshi E, Tobler PN, Tremblay L. Ventral pallidum encodes contextual information and controls aversive behaviors. Cereb Cortex. 2016;27:2528-43.

34. Swanson LW, Cowan WM. A note on the connections and development of the nucleus accumbens. Brain Res. 1975;92:324-30.

35. Williams DJ, Crossman AR, Slater P. The efferent projections of the nucleus accumbens in the rat. Brain Res. 1977;130:217-27.

36. Heimer L, Switzer RD, Van Hoesen GW. Ventral striatum and ventral pallidum: components of the motor system? Trends Neurosci. 1982;5:83-7.

37. Mogenson GJ, Jones DL, Yim CY. From motivation to action: functional interface between the limbic system and the motor system. Prog Neurobiol. 1980;14:69-97.

38. Kalivas PW, Volkow ND. The neural basis of addiction: a pathology of motivation and choice. Am J Psychiatry. 2005;162:1403-13.

39. Smith KS, Tindell AJ, Aldridge JW, Berridge KC. Ventral pallidum roles in reward and motivation. Behav Brain Res. 2009;196:155-67.

40. Tachibana $Y$, Hikosaka $O$. The primate ventral pallidum encodes expected reward value and regulates motor action. Neuron. 2012;76:826-37.

41. Pessiglione $M$, Schmidt L, Draganski B, Kalisch R, Lau H, Dolan RJ, et al. How the brain translates money into force: a neuroimaging study of subliminal motivation. Science. 2007;316:904-6.

42. Richard JM, Ambroggi F, Janak PH, Fields HL. Ventral pallidum neurons encode incentive value and promote cue-elicited instrumental actions. Neuron. 2016;90:1165-73.

43. Root DH, Ma S, Barker DJ, Megehee L, Striano BM, Ralston CM, et al. Differential roles of ventral pallidum subregions during cocaine self-administration behaviors. J Comp Neurol. 2013;521:558-88.

44. Perry CJ, McNally GP. A role for the ventral pallidum in context-induced and primed reinstatement of alcohol seeking. Eur J Neurosci. 2013;38:2762-73.

45. Prasad AA, McNally GP. Ventral pallidum output pathways in context-induced reinstatement of alcohol seeking. J Neurosci. 2016;36:11716-26.

46. Rogers JL, Ghee S, See RE. The neural circuitry underlying reinstatement of heroin-seeking behavior in an animal model of relapse. Neuroscience. 2008;151:579-88.

47. Mahler SV, Vazey EM, Beckley JT, Keistler CR, McGlinchey EM, Kaufling J, et al. Designer receptors show role for ventral pallidum input to ventral tegmental area in cocaine seeking. Nat Neurosci. 2014;17:577. 
48. Hubner CB, Koob GF. The ventral pallidum plays a role in mediating cocaine and heroin self-administration in the rat. Brain Res. 1990;508:20-9.

49. Prasad AA, McNally GP. Ventral pallidum and alcohol addiction. In: Preedy VR, editor. Neuroscience of alcohol. Cambridge: Academic Press; 2019. p. 163-70.

50. McFarland K, Kalivas PW. The circuitry mediating cocaine-induced reinstatement of drug-seeking behavior. J Neurosci. 2001;21:8655-63.

51. McFarland K, Davidge SB, Lapish CC, Kalivas PW. Limbic and motor circuitry underlying footshock-induced reinstatement of cocaine-seeking behavior. J Neurosci. 2004;24:1551-60.

52. Churchill L, Kalivas PW. A topographically organized gamma-aminobutyric acid projection from the ventral pallidum to the nucleus accumbens in the rat. J Comp Neurol. 1994;345:579-95.

53. Groenewegen HJ, Berendse HW, Haber SN. Organization of the output of the ventral striatopallidal system in the rat: ventral pallidal efferents. Neuroscience. 1993;57:113-42.

54. Root DH, Melendez RI, Zaborszky L, Napier TC. The ventral pallidum: subregionspecific functional anatomy and roles in motivated behaviors. Prog Neurobiol. 2015;130:29-70.

55. Smith KS, Berridge KC. Opioid limbic circuit for reward: interaction between hedonic hotspots of nucleus accumbens and ventral pallidum. J Neurosci. 2007;27:1594-605.

56. Smith KS, Berridge KC. The ventral pallidum and hedonic reward: neurochemical maps of sucrose "liking" and food intake. J Neurosci. 2005;25:8637-49.

57. Calder AJ, Beaver JD, Davis MH, van Ditzhuijzen J, Keane J, Lawrence AD. Disgust sensitivity predicts the insula and pallidal response to pictures of disgusting foods. Eur J Neurosci. 2007;25:3422-8.

58. Beaver JD, Lawrence AD, van Ditzhuijzen J, Davis MH, Woods A, Calder AJ. Individual differences in reward drive predict neural responses to images of food. J Neurosci. 2006;26:5160-6.

59. Stefanik MT, Kupchik YM, Brown RM, Kalivas PW. Optogenetic evidence that pallidal projections, not nigral projections, from the nucleus accumbens core are necessary for reinstating cocaine seeking. J Neurosci. 2013;33:13654-62.

60. Zahm DS, Heimer L. Two transpallidal pathways originating in the rat nucleus accumbens. J Comp Neurol. 1990;302:437-46.

61. Knowland D, Lilascharoen V, Pacia CP, Shin S, Wang EH, Lim BK. Distinct ventral pallidal neural populations mediate separate symptoms of depression. Cell. 2017;170:284-97.

62. Wulff AB, Tooley J, Marconi $\sqcup$, Creed MC. Ventral pallidal modulation of aversion processing. Brain Res. 2018;1713:62-9.

63. Stephenson-Jones M. Pallidal circuits for aversive motivation and learning. Curr Opin. Behav Sci. 2019;26:82-9.

64. Armbruster BN, Li X, Pausch MH, Herlitze S, Roth BL. Evolving the lock to fit the key to create a family of $\mathrm{G}$ protein-coupled receptors potently activated by an inert ligand. Proc Natl Acad Sci. 2007;104:5163-8.

65. National Research Council. Guide for the care and use of laboratory animals. Washington, DC: The National Academies Press; 2010.

66. Mahler SV, Aston-Jones G. CNO evil? Considerations for the use of DREADDs in behavioral neuroscience. Neuropsychopharmacology. 2018;43:934.

67. MacLaren DA, Browne RW, Shaw JK, Krishnan Radhakrishnan S, Khare P, España $\mathrm{RA}$, et al. Clozapine $\mathrm{N}$-oxide administration produces behavioral effects in Long-Evans rats: implications for designing DREADD experiments. eNeuro. 2016;3:0219-16. ENEURO2016.

68. Gomez JL, Bonaventura J, Lesniak W, Mathews WB, Sysa-Shah P, Rodriguez LA, et al. Chemogenetics revealed: DREADD occupancy and activation via converted clozapine. Science. 2017;357:503-7.

69. Zhou L, Pruitt C, Shin CB, Garcia AD, Zavala AR, See RE. Fos expression induced by cocaine-conditioned cues in male and female rats. Brain Struct Funct. 2014;219:1831-40.

70. Kohtz AS, Aston-Jones G. Cocaine seeking during initial abstinence is driven by noradrenergic and serotonergic signaling in hippocampus in a sex-dependent manner. Neuropsychopharmacology. 2017;42:408.

71. Marchant NJ, Rabei R, Kaganovsky K, Caprioli D, Bossert JM, Bonci A, et al. A critical role of lateral hypothalamus in context-induced relapse to alcohol seeking after punishment-imposed abstinence. J Neurosci. 2014; 34:7447-57.

72. Krasnova IN, Marchant NJ, Ladenheim B, McCoy MT, Panlilio LV, Bossert JM, et al. Incubation of methamphetamine and palatable food craving after punishmentinduced abstinence. Neuropsychopharmacology. 2014;39:2008.

73. Marchant NJ, Campbell EJ, Whitaker LR, Harvey BK, Kaganovsky K, Adhikary S, et al. Role of ventral subiculum in context-induced relapse to alcohol seeking after punishment-imposed abstinence. J Neurosci. 2016;36:3281-94.

74. Ferster CB, Skinner BF. Schedules of reinforcement. Upper Saddle River, NJ: Prentice-Hall, Inc; 1957.

75. Orsini CA, Willis ML, Gilbert RJ, Bizon JL, Setlow B. Sex differences in a rat model of risky decision making. Behav Neurosci. 2016;130:50.
76. Pelloux Y, Everitt BJ, Dickinson A. Compulsive drug seeking by rats under punishment: effects of drug taking history. Psychopharmacology. 2007;194:127-37.

77. Blanchard RJ, Blanchard DC, Weiss SM, Meyer S. The effects of ethanol and diazepam on reactions to predatory odors. Pharmacol Biochem Behav. 1990;35:775-80.

78. Blanchard DC, Griebel G, Pobbe R, Blanchard RJ. Risk assessment as an evolved threat detection and analysis process. Neurosci Biobehav Rev. 2011;35:991-8.

79. Hunt HF, Brady JV. Some effects of punishment and intercurrent "anxiety" on a simple operant. J Comp Physiological Psychol. 1955;48:305.

80. Kruzich PJ, See RE. Differential contributions of the basolateral and central amygdala in the acquisition and expression of conditioned relapse to cocaineseeking behavior. J Neurosci. 2001;21:RC155.

81. Mahler SV, Brodnik ZD, Cox BM, Buchta WC, Bentzley BS, Quintanilla J, et al. Chemogenetic manipulations of ventral tegmental area dopamine neurons reveal multifaceted roles in cocaine abuse. J Neurosci. 2019;39:503-18.

82. Fuchs RA, Evans KA, Ledford CC, Parker MP, Case JM, Mehta RH, et al. The role of the dorsomedial prefrontal cortex, basolateral amygdala, and dorsal hippocampus in contextual reinstatement of cocaine seeking in rats. Neuropsychopharmacology. 2005;30:296.

83. Mahler SV, Smith RJ, Aston-Jones G. Interactions between VTA orexin and glutamate in cue-induced reinstatement of cocaine seeking in rats. Psychopharmacology. 2013;226:687-98.

84. Bossert JM, Stern AL, Theberge FR, Marchant NJ, Wang HL, Morales M, et al. Role of projections from ventral medial prefrontal cortex to nucleus accumbens shell in context-induced reinstatement of heroin seeking. J Neurosci. 2012;32:4982-91.

85. Bonaventura J, Eldridge MAG, Hu F, Gomez JL, Sanchez-Soto M, Abramyan AM, et al. High-potency ligands for DREADD imaging and activation in rodents and monkeys. Nat Commun. (in press).

86. McReynolds JR, Christianson JP, Blacktop JM, Mantsch JR. What does the Fos say? Using Fos-based approaches to understand the contribution of stress to substance use disorders. Neurobiol stress. 2018;9:271-85.

87. Zahm DS, Heimer L. Ventral striatopallidal parts of the basal ganglia in the rat: I. Neurochemical compartmentation as reflected by the distributions of neurotensin and substance P immunoreactivity. J Comp Neurol. 1988;272:516-35.

88. Paxinos $G$, Watson $C$. The rat brain in stereotaxic coordinates: hard cover edition. London: Elsevier; 2006.

89. Chang SE, Todd TP, Bucci DJ, Smith KS. Chemogenetic manipulation of ventral pallidal neurons impairs acquisition of sign-tracking in rats. Eur J Neurosci. 2015;42:3105-16.

90. Van Haaren F, Meyer ME. Sex differences in locomotor activity after acute and chronic cocaine administration. Pharmacol Biochem Behav. 1991;39:923-7.

91. American Psychiatric Association. Diagnostic and statistical manual of mental disorders (DSM- $\left.{ }^{\oplus}\right)$. Washington, DC: American Psychiatric Association Publications; 2013.

92. Badiani A, Belin D, Epstein D, Calu D, Shaham Y. Opiate versus psychostimulant addiction: the differences do matter. Nat Rev Neurosci. 2011;12:685.

93. Shalev U, Grimm JW, Shaham Y. Neurobiology of relapse to heroin and cocaine seeking: a review. Pharmacol Rev. 2002;54:1-42.

94. Bossert JM, Ghitza UE, Lu L, Epstein DH, Shaham Y. Neurobiology of relapse to heroin and cocaine seeking: an update and clinical implications. Eur J Pharmacol. 2005;526:36-50.

95. Mantsch JR, Baker DA, Funk D, Lê AD, Shaham Y. Stress-induced reinstatement of drug seeking: 20 years of progress. Neuropsychopharmacology. 2016;41:335.

96. Li Q, Li W, Wang H, Wang Y, Zhang Y, Zhu J, et al. Predicting subsequent relapse by drug-related cue-induced brain activation in heroin addiction: an event-related functional magnetic resonance imaging study. Addiction Biol. 2015;20:968-78.

97. Bouton ME. Extinction of instrumental (operant) learning: interference, varieties of context, and mechanisms of contextual control. Psychopharmacology. 2019;236:7-19.

98. Prasad AA, Xie C, Chaichim C, Killcross S, Power JM, McNally GP. Complementary roles for ventral pallidum cell types and their projections in relapse. bioRxiv. 2019: https://doi.org/10.1101/533554.

99. Floresco SB. The nucleus accumbens: an interface between cognition, emotion, and action. Annu Rev Psychol. 2015;66:25-52.

100. Salamone JD, Correa M, Farrar A, Mingote SM. Effort-related functions of nucleus accumbens dopamine and associated forebrain circuits. Psychopharmacology. 2007;191:461-82.

101. Carelli RM, ljames SG, Crumling AJ. Evidence that separate neural circuits in the nucleus accumbens encode cocaine versus "natural" (water and food) reward. J Neurosci. 2000;20:4255-66.

102. Day JJ, Wheeler RA, Roitman MF, Carelli RM. Nucleus accumbens neurons encode Pavlovian approach behaviors: evidence from an autoshaping paradigm. Eur J Neurosci. 2006;23:1341-51. 
Ventral pallidum is essential for cocaine relapse after voluntary... MR. Farrell et al.

103. Ambroggi F, Ishikawa A, Fields HL, Nicola SM. Basolateral amygdala neurons facilitate reward-seeking behavior by exciting nucleus accumbens neurons. Neuron. 2008;59:648-61.

104. Fuchs RA, Ramirez DR, Bell GH. Nucleus accumbens shell and core involvement in drug context-induced reinstatement of cocaine seeking in rats. Psychopharmacology. 2008;200:545-56.

105. McFarland K, Lapish CC, Kalivas PW. Prefrontal glutamate release into the core of the nucleus accumbens mediates cocaine-induced reinstatement of drugseeking behavior. J Neurosci. 2003;23:3531-7.
106. Smedley EB, DiLeo A, Smith KS. Circuit directionality for motivation: lateral accumbens-pallidum, but not pallidum-accumbens, connections regulate motivational attraction to reward cues. Neurobiol Learn Mem. 2019;162:23-35.

107. Chang SE, Todd TP, Smith KS. Paradoxical accentuation of motivation following accumbens-pallidum disconnection. Neurobiol Learn Mem. 2018;149:39-45.

108. Ottenheimer D, Richard JM, Janak PH. Ventral pallidum encodes relative reward value earlier and more robustly than nucleus accumbens. Nat Commun 2018;9:4350. 